\title{
Day-to-Day Variation of Early Repolarization Pattern Predicts Life-Threatening Arrhythmias in Patients With Brugada Syndrome
}

\author{
Naruya Ishizue, MD; Shinichi Niwano, MD; Hidehira Fukaya, MD; \\ Jun Oikawa, MD; Jun Kishihara, MD; Junya Ako, MD
}

\begin{abstract}
Background: We assessed the relationship between day-to-day variation of the early repolarization (ER) pattern and ventricular tachyarrhythmia (VTA) events in Brugada syndrome (BrS) patients because the clinical implications are unclear.

Methods and Results: This retrospective study consisted of 41 patients with BrS who underwent implantable cardioverter-defibrillator (ICD) implantation. BrS was diagnosed by a spontaneous or drug-induced type 1 ECG without structural heart disease. Day-to-day variation of the ER pattern was defined as temporal change in the J-point $(\geq 0.1 \mathrm{mV})$ on ECG. VTA events were detected via ICD interrogation: 15 patients experienced VTA events during $124 \pm 62$ months' observation. Day-to-day variation of the ER pattern was positive in 7 patients (17\%). In the multivariate Cox proportional hazards model, day-to-day variation of a positive ER pattern (hazard ratio [HR]: $3.475,95 \%$ confidence interval $[\mathrm{Cl}]: 1.105-10.414, \mathrm{P}=0.034)$ and documented history of VTA (HR: $4.802,95 \% \mathrm{Cl}$ : 1.547-17.995, $P=0.006$ ) were independent predictors of VTA events. In patients with electrical storm ( $E S: n=9$ ), day-to-day variation of the ER pattern was positive in 5 patients $(56 \%)$. ES events were more frequently observed in patients with a positive day-to-day variation of $E R$ pattern than in those without $(P<0.05)$.
\end{abstract}

Conclusions: The incidence of day-to-day variation of the ER pattern was higher in patients with arrhythmic events of VTA and/or ES among BrS patients with ICD.

Key Words: Brugada syndrome; Dynamicity of early repolarization; J-wave syndrome; Sudden cardiac death

B rugada syndrome $(\mathrm{BrS})$, which is characterized by ST segment and J-point elevation in the right precordial leads on 12-lead ECG, is known as an important risk for sudden cardiac death (SCD). ${ }^{1}$ Although the importance of implantable cardioverter defibrillator (ICD) implantation is well understood for patients with a history of ventricular fibrillation (VF) episodes, its indication is still controversial for asymptomatic BrS patients. Guidelines recommend ICD implantation in high-risk patients, but the criteria for such patients varies in several guidelines, ${ }^{2-4}$ and risk stratification to expect arrhythmic events needs more discussion about this criteria. The early repolarization (ER) pattern is characterized by $\mathrm{J}$-point elevation of the terminal part of the QRS complex with notching or a slurred appearance on the surface ECG. ${ }^{5}$ Although it was previously considered as a normal variant, it has recently been reported to be related to life-threatening ventricular arrhythmias in patient with several organic heart diseases. ${ }^{58}$ Because BrS and the ER syndrome are assumed to be based on a common arrhythmic platform related to the transmural electrical current, Antzelevitch and Yan proposed the J-wave syndrome as a concept of the primary arrhythmia relating to life-threatening events. ${ }^{9}$ In clinical practice, most cases of the ER pattern are benign and patients are not believed to be at increased risk of arrhythmogenicity, however, the J-point amplitude and its dynamicity (i.e., circadian and/or day-to-day variation) have been focused on as predictive parameters for arrhythmogenicity in specific cases. ${ }^{\mathbf{1 0 - 1 2}}$ Because it is well known that the ER pattern frequently coexists in $\mathrm{BrS},{ }^{13}$ we sought to evaluate the ER pattern and its dynamicity as predictive factors for arrhythmic events in BrS. In this study we assessed the relationship between day-to-day variation of the ER pattern and ventricular tachyarrhythmia (VTA) events in patients with $\mathrm{BrS}$.

\section{Methods}

\section{Study Population and the Diagnostic Criteria Test}

The study population consisted of 41 consecutive patients with BrS with ICD implantation at Kitasato University Hospital between 2000 and 2016. The 41 patients were

Received February 18, 2020; revised manuscript received August 10, 2020; accepted August 24, 2020; J-STAGE Advance Publication released online November 13, 2020 Time for primary review: 22 days

Department of Cardiovascular Medicine, Kitasato University School of Medicine, Sagamihara, Japan

Mailing address: Naruya Ishizue, MD, Department of Cardiovascular Medicine, Kitasato University School of Medicine, 1-15-1 Kitasato, Minami-ku, Sagamihara 252-0374, Japan. E-mail: n_ishizue@med.kitasato-u.ac.jp

All rights are reserved to the Japanese Circulation Society. For permissions, please e-mail: cj@j-circ.or.jp

ISSN-1346-9843 
Follow up period: $124 \pm 62$ months

ICD implanted patients BrS at our institute between 2000 and 2016 $(\mathbf{n}=41)$

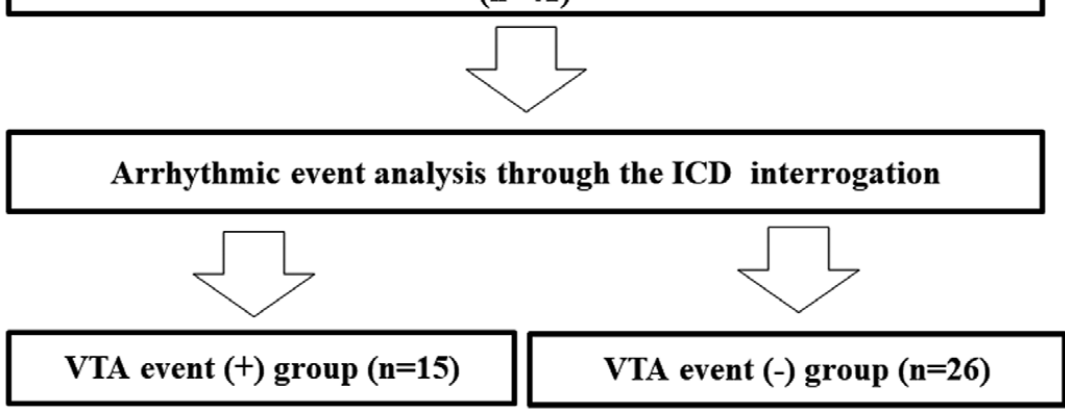

Figure 1. Classification of the study population according to ventricular tachyarrhythmia (VTA) events. The 41 consecutive patients with $\mathrm{BrS}$ and an ICD implanted between 2000 and 2016 were divided into 2 groups according to VTA events during the observation period after ICD implantation. VTA event defined as an ICD appropriate shock for ventricular arrhythmia. BrS, Brugada syndrome; ICD, implantable cardioverter-defibrillator.

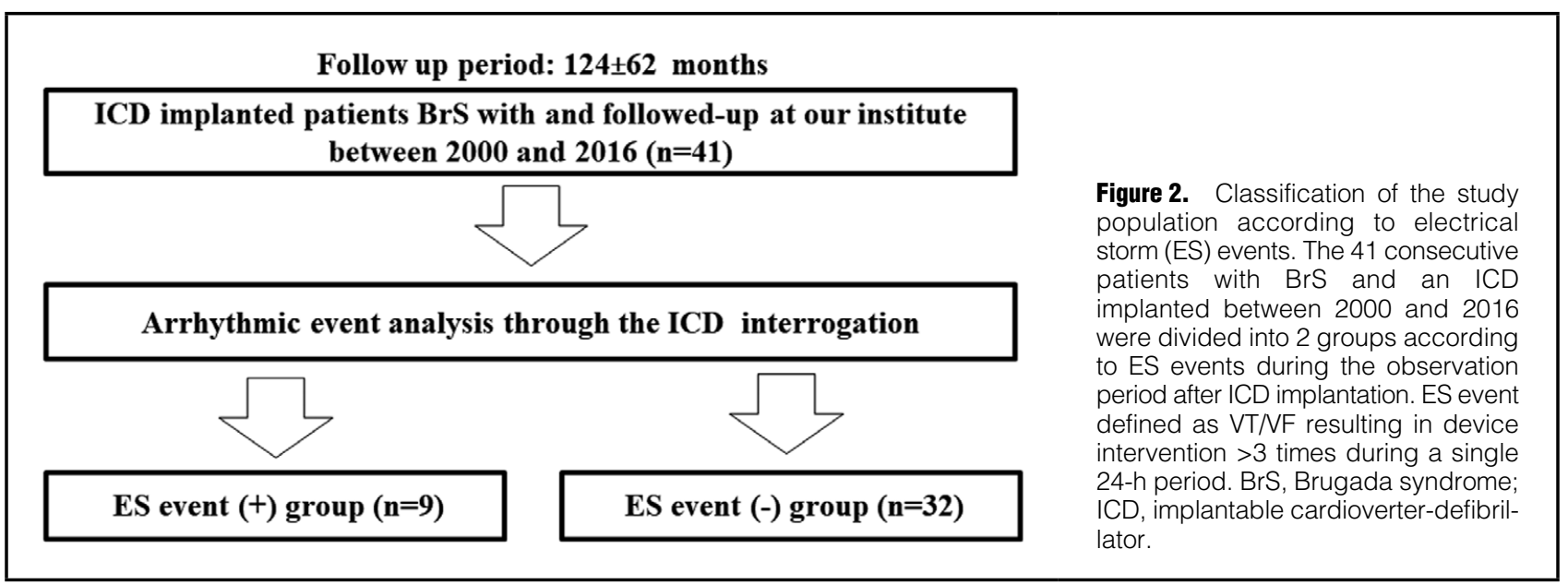

divided into 2 groups according to VTA and electrical storm (ES) events during the observation period after ICD implantation (Figures 1,2). ES was defined as VTA resulting in device intervention $>3$ times during a single 24 -h period. ${ }^{14}$ In this study, BrS was diagnosed only by the presence of type 1 Brugada pattern ST-segment elevation on ECG (coved type) with criteria including symptoms, inducible VTA during electrophysiological studies, or with a family history of SCD or positive genetic findings with the absence of any structural myocardial diseases. ${ }^{15}$ A type 1 ECG was defined as coved ST-segment elevation displaying an amplitude of the QRS-ST junction $\geq 2 \mathrm{~mm}$ followed by a negative $\mathrm{T}$-wave, placed in the $4 \mathrm{th}$, 3rd, or 2 nd intercostal space either at baseline or after the administration of a sodium-channel blocking agent. In the provocation test of ST-segment elevation, pilsicainide $(1 \mathrm{mg} / \mathrm{kg})$ was administered intravenously over a 10 -min period. ICD implantation was indicated in each patient for primary or secondary prevention of life-threatening arrhythmic events in according with recommendations by the guidelines. ${ }^{16}$ Programmed electrical stimulation was delivered from the right ventricular apex and outflow tract with a maximum of 3 ventricular extra stimuli at 2 pacing cycle lengths. Stimulation was performed at twice the pacing threshold. Results of programmed electrical stimulation were defined as positive when VF with collapse and requiring shock was induced. All studies were performed under approval from the Clinical Studies and Ethics Committee of Kitasato University Hospital.

\section{Recording and Analysis of the 12-Lead ECG}

The 12-lead ECGs were recorded using a standard recorder (Cardio star FCP-7541, Fukuda Co. Ltd., Tokyo, Japan) with standard positions for the recording leads. Data were digitally stored with frequency of $500 \mathrm{~Hz}$ in the ECG data server of Kitasato University Hospital. Heart rate, PQ interval, QRS duration, QT interval, and corrected QT interval (using Bazzett's formula) were measured on 12-lead ECGs recorded after ICD implantation, and at each ICD interrogation performed during the daytime (09:00-17:00 hours) in the device outpatient clinic. Because frequency of visits causes sampling biases, ECG recordings from regular visits every 4-6 months were used for the analysis in this study.

The ER pattern was defined as a J-point elevation $\geq 0.1 \mathrm{mV}$ above the baseline, with notching and/or slurred appearance of the terminal part of the QRS complex in at least 2 contiguous leads of the inferior leads (II, III, aVF) and/or lateral leads (I, aVL, V4-6) (Figure 3A). ${ }^{5}$ In this study we evaluated the ST-segment patterns after the 
A)

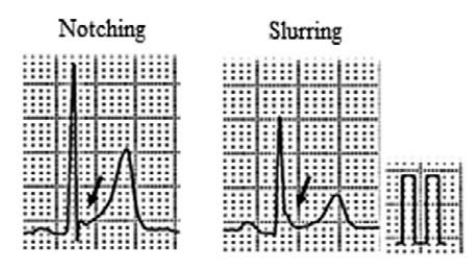

B)

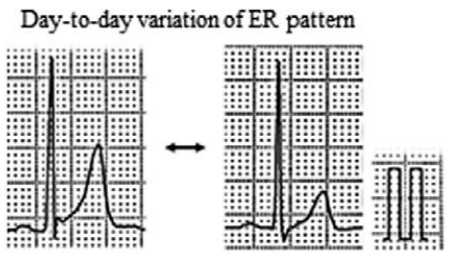

C)

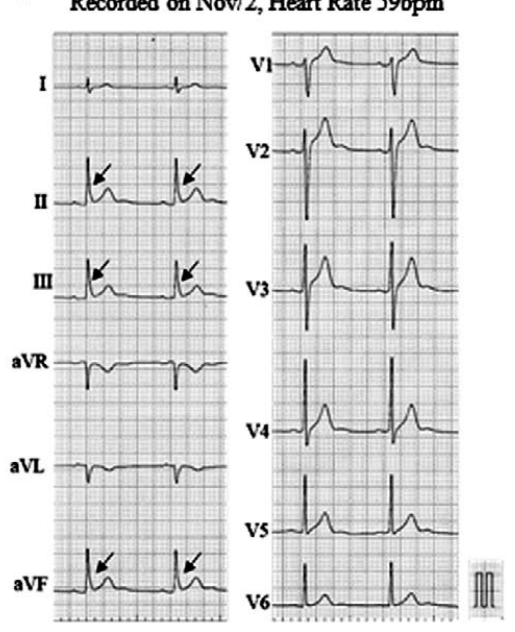

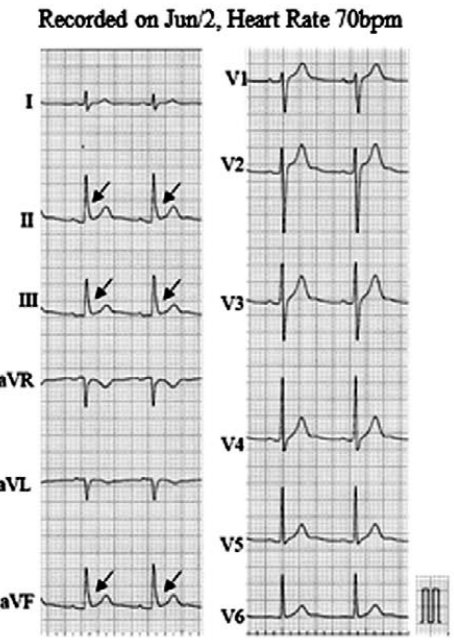

Figure 3. Definition of early repolarization (ER) pattern and its daily variations. (A) ER pattern was defined as a J-point elevation $(\geq 0.1 \mathrm{mV})$, notching, or a slurred appearance of the terminal part of the QRS complex in inferior (II, III, aVF) or lateral leads (I, aVL, V4-6). (B) Day-to-day variation of the ER pattern defined as a temporal increase or decrease in the amplitude of the J-point $(\geq 0.1 \mathrm{mV})$ in the same lead during the stable phase during the daytime on 12-lead ECG. (C) 12-lead ECGs recorded in another day during the stable phase. Right-side ECG shows ER pattern followed by ascending/upsloping ST-segment elevation in the inferior leads (arrows). However, the amplitude of the ER pattern does not alternate, so this case was judged as negative day-to-day variation.

J-point with either ascending or horizontal/descending waveform and dynamicity of the ER pattern as day-to-day variation of the ER pattern. Day-to-day variation of ER pattern was defined as a temporal change in the J-point amplitude $(\geq 0.1 \mathrm{mV})$ in the same lead during ECG recording at the time of the ICD interrogation. Disappearance and appearance of the ER pattern $\geq 0.1 \mathrm{mV}$, and exaggeration of the amplitude of the ER pattern from $0.1 \mathrm{mV}$ to $\geq 0.2 \mathrm{mV}$ were defined as positive day-to-day variation (Figures 3B,3C,4). Abnormal fragmentation of the QRS complex (f-QRS) was defined as the presence of multiple spikes within the QRS ( $\geq 4$ spikes in 1 or $\geq 8$ spikes in all of leads V1-3). ${ }^{17}$ The $\mathrm{T}$ peak-end was measured in each precordial lead as the difference between the QT interval and QT peak interval; measured from the beginning of the QRS until the peak of the T-wave. In the case of negative or biphasic T-waves, the QT peak was measured to the nadir of the $\mathrm{T}$-wave. $\mathrm{T}$-waves smaller than $1.5 \mathrm{~mm}$ in amplitude were not measured. The $\mathrm{T}$ peak-end interval was the maximum obtained in all precordial leads. ${ }^{18}$ The presence of an $\mathrm{S}$-wave in leads I was examined. The amplitude from the isoelectric line to the nadir of the $\mathrm{S}$-wave and the duration from the beginning to the end of the S-wave in lead I were measured with calipers. ${ }^{19}$

All measurements of ECG parameters were performed by 2 investigators blinded to other clinical parameters.

\section{ICD Programming and Interrogation}

All defibrillator systems were implanted in the pectoral region, and all leads were successfully implanted via a transvenous approach. Patients were followed up under the same 1-zone therapeutic setting (i.e., $1 \mathrm{VF}$ zone). The fibrillation detection interval (FDI) used default settings (FDI of $300 \mathrm{~ms}$ ). Device interrogations were repeated in every 4-6 months in the device outpatient clinic. Each therapeutic episode was analyzed by expert electrophysiologists, and only true ventricular tachycardia (VT) or VF requiring appropriate therapies were counted as VTA events in the present study.

\section{Clinical Data Analysis}

Serum laboratory data and transthoracic echocardiography were routinely evaluated 1 month after ICD implantation. In each set of echocardiographic data, left ventricular diastolic and systolic dimensions were evaluated, and the left ventricular ejection fraction was calculated using the modified Simpson's method.

\section{Statistical Analysis}

Statistical analysis was performed using JMP 11.2 statistical software package (SAS Institute, Cary, NC, USA). Continuous variables are presented as the mean \pm standard deviation, and were compared using the Student's t-test or Mann-Whitney U test. Discontinuous variables are presented as numbers and percentages and were compared using the Fisher exact test. The clinical parameters were compared between patients with and without VTA events or between patients with and without ES events. In the multivariable analysis, variables were selected by the stepwise method from parameters with $\mathrm{P}$ values $<0.05$ in the univariate analysis. $\mathrm{P}<0.05$ was considered significant.

\section{Results}

\section{Clinical Characteristics}

The clinical characteristics of the 41 patients are summarized in Table 1. The mean age was $46 \pm 14$ years and $97 \%$ were male. All ECG parameters, namely heart rate, PR 


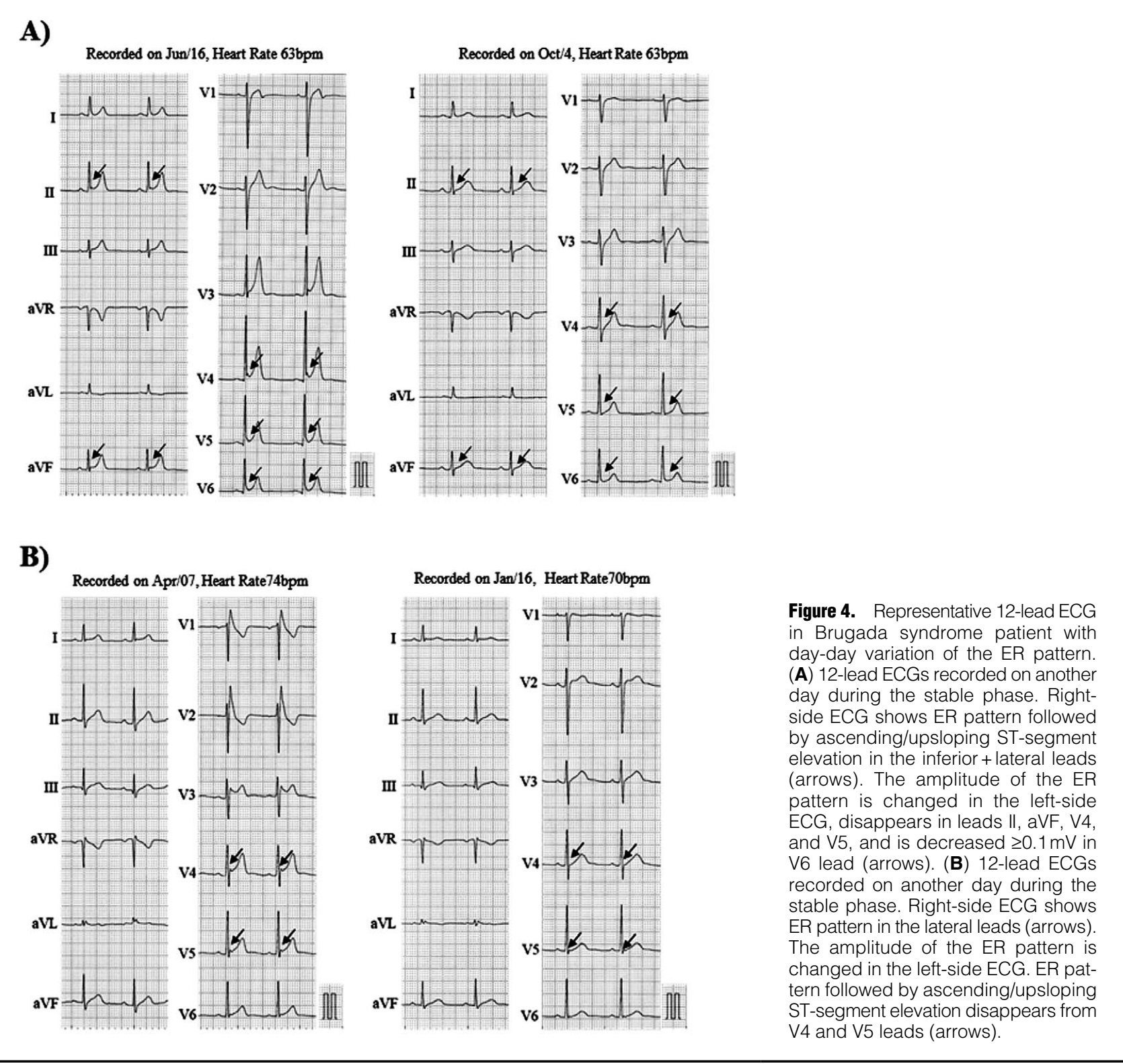

interval, QRS duration, and QTc, and the echocardiographic parameter were within normal range. A total of 10 patients had a family history of SCD, and 18 patients had a documented history of VF. Spontaneous type 1 ECG was observed in 17 patients. Programmed electrical stimulation induced VF in $90 \%$ of patients. ICD was implanted for the purpose of secondary prevention of SCD in 18 patients and for primary prevention in the remaining 23 patients. Out of all 41 patients, 13 exhibited an ER pattern on 12-lead ECG (Figure 3C). Of these 13 patients, 3 patients showed the ER pattern in lateral leads, 7 patients showed it in inferior leads, and 3 patients showed it in inferior + lateral leads. Seven patients exhibited day-to-day variation (i.e., temporal change in $\mathrm{J}$-point amplitude $\geq 0.1 \mathrm{mV}$ ) (Figure 4).

\section{Comparison of Patients With and Without VTA Events}

During the observation period of $124 \pm 62$ months, VTA and/or ES events occurred in 15 and 9 patients, respectively (Figures 1,2). Table 2 shows the comparison of patients with and without VTA events ( $n=15$ and 26, respectively). Incidence of family history of SCD and history of syncope did not differ between the 2 groups (VTA event (+) group vs. VTA event (-) group: family history of SCD $20 \%$ vs. $27 \%, \mathrm{P}=0.619$; history of syncope $13 \%$ vs. $27 \%, \mathrm{P}=0.311$ ). The ER pattern was observed in 7 of 15 patients in the VTA event (+) group (47\%), and in 6 of 26 patients in the VTA event (-) group (23\%). The incidence of the ER pattern did not differ between the 2 groups $(\mathrm{P}=0.168)$. On the other hand, day-to-day variation of the ER pattern was more frequently observed in the VTA event $(+)$ group than in the VTA event $(-)$ group $(40 \%$ vs. $4 \%, \mathrm{P}<0.05)$. The incidence of a documented history of VF was higher in the VTA event $(+)$ group than in the VTA event (-) group (73\% vs. $27 \%, \mathrm{P}<0.05)$. Additionally, the incidence of the presence of the ER pattern in inferior + lateral leads was 
Table 1. Baseline Characteristics of the Study Population

Total $(n=41)$

\begin{tabular}{|c|c|}
\hline \multicolumn{2}{|l|}{ Demographic date } \\
\hline Sex male, $\mathrm{n}(\%)$ & $40(97)$ \\
\hline Age (years) & $46 \pm 14$ \\
\hline Family history of SCD, $\mathrm{n}(\%)$ & $10(24)$ \\
\hline History of syncope, $n(\%)$ & $9(22)$ \\
\hline Documented history of VF, n (\%) & $18(44)$ \\
\hline $\begin{array}{l}\text { Inducibility of VTA with programmed } \\
\text { ventricular stimulation, } \mathrm{n} / \mathrm{N}(\%)\end{array}$ & $26 / 29(90)$ \\
\hline VTA event, $\mathrm{n}(\%)$ & $15(37)$ \\
\hline ES event, $\mathrm{n}(\%)$ & $9(22)$ \\
\hline \multicolumn{2}{|l|}{ ICD indication } \\
\hline Primary prevention, $\mathrm{n}(\%)$ & $23(56)$ \\
\hline Secondary prevention, $\mathrm{n}(\%)$ & $18(44)$ \\
\hline \multicolumn{2}{|l|}{ Laboratory data } \\
\hline $\mathrm{Cr}(\mathrm{mg} / \mathrm{dL})$ & $0.85 \pm 0.17$ \\
\hline $\mathrm{Na}(\mathrm{mEq} / \mathrm{L})$ & $141.2 \pm 1.6$ \\
\hline $\mathrm{K}(\mathrm{mEq} / \mathrm{L})$ & $4.16 \pm 0.34$ \\
\hline BNP (pg/dL) & $13.5 \pm 15.7$ \\
\hline \multicolumn{2}{|l|}{ Echocardiographic parameters } \\
\hline EF (\%) & $67 \pm 5$ \\
\hline LVDd (mm) & $44 \pm 11$ \\
\hline LVDs (mm) & $27 \pm 8$ \\
\hline \multicolumn{2}{|l|}{ Electrocardiographic parameters } \\
\hline No. of analyzed ECGs, $n$ & $34 \pm 19$ \\
\hline Heart rate (beats/min) & $66 \pm 11$ \\
\hline PR interval (ms) & $163 \pm 25$ \\
\hline QRS duration (ms) & $107 \pm 10$ \\
\hline $\mathrm{QTc}(\mathrm{ms})$ & $406 \pm 21$ \\
\hline Spontaneous type 1 ECG, n (\%) & $17(41)$ \\
\hline Fragmented QRS, n (\%) & $7(17)$ \\
\hline S-wave in lead I, n (\%) & $20(49)$ \\
\hline Tpeak-end interval (ms) & $107 \pm 15$ \\
\hline Tpeak-end dispersion (ms) & $27 \pm 10$ \\
\hline ER pattern, n (\%) & $13(32)$ \\
\hline ER pattern in lateral leads, $\mathrm{n}(\%)$ & $3(7)$ \\
\hline ER pattern in inferior leads, $n(\%)$ & $7(17)$ \\
\hline ER pattern in inferior + lateral leads, $\mathrm{n}(\%)$ & $3(20)$ \\
\hline Day-to-day variation of ER pattern, $\mathrm{n}(\%)$ & $7(17)$ \\
\hline Notching of ER pattern, $\mathrm{n}(\%)$ & $5(12)$ \\
\hline Slurring of ER pattern, $n(\%)$ & $10(24)$ \\
\hline ER pattern with ascending ST-segment, $\mathrm{n}(\%)$ & $8(20)$ \\
\hline $\begin{array}{l}\text { ER pattern with horizontal/descending } \\
\text { ST-segment, } \mathrm{n}(\%)\end{array}$ & $5(12)$ \\
\hline
\end{tabular}

BNP, B-type natriuretic peptide; CR, creatinine; ER, early repolarization; ICD, implantable cardioverter defibrillator; LVDd, left ventricular diastolic diameter; LVDs, left ventricular systolic diameter; EF, ejection fraction; ES, electrical storm; SCD, sudden cardiac death; VF, ventricular fibrillation; VTA, ventricular tachyarrhythmia.

more frequently observed in the VTA event $(+)$ group than in the VTA event $(-)$ group $(20 \%$ vs. $0 \%, \mathrm{P}<0.05)$.

\section{Predictive Factors for Future VTA Events}

Table 3 shows the result of analysis using the multivariate Cox proportional hazards models. Day-to-day variation of the ER pattern (hazard ratio [HR]: $3.475,95 \%$ confidence interval $[\mathrm{CI}]: 1.105-10.414, \mathrm{P}<0.05)$ and a documented history of VF (HR: $4.802,95 \%$ CI: $1.547-17.995$, P<0.05) were independent predictors of future VTA events patients with $\mathrm{BrS}$ during the observation period.

\section{Comparison of Patients With and Without ES Events}

During the observation period, ES events occurred in 9 of the 41 patients (Figure 2). Fortunately, all of 9 patients could avoid SCD through appropriate shock therapy by the ICD. Table 4 shows the comparison of patients with and without ES events during the observation period. The incidence of the ER pattern and the ER pattern in inferior + lateral leads tended to be higher in the ES event (+) group than in the ES event (-) group, although the difference was not statistically significant (ES event $(+)$ group vs. ES event (-) group: ER pattern $56 \%$ vs. $25 \%, \mathrm{P}=0.113$; ER pattern in inferior + lateral leads $22 \%$ vs. $3 \%, \mathrm{P}=0.116$ ). Day-to-day variation of the ER pattern was more frequently observed in the ES event $(+)$ group than in the ES event (-) group $(56 \%$ vs. $6 \%, \mathrm{P}<0.05)$. The incidence of a documented history of VF was higher in the ES event $(+)$ group than in the ES event (-) group ( $78 \%$ vs. $34 \%, \mathrm{P}<0.05$ ).

\section{Discussion}

In the present study, we retrospectively compared the clinical factors between patients with and without fatal arrhythmic events among patients with BrS and ICD implantation. The incidence of day-to-day variation of the ER pattern as well as a history of documented VF were higher in the patient groups with VTA and/or ES, which suggested they are predictors for future fatal arrhythmic events in patients with BrS.

\section{ER Pattern in Patients With BrS}

ER pattern and $\mathrm{BrS}$ are considered to reflect abnormal electrical gradients in the ventricular wall. They have been reported as possible risks for life-threatening arrhythmic events. ${ }^{5-9}$ Due to such similar and common electrophysiological background, patients with these ECG characteristics are categorized as J-wave syndrome. ${ }^{9}$ Previous study reported that the anterior ER variant, characterized as including the RSR' type ST-segment elevation in the anterior chest leads and $\mathrm{J}$-wave, was similar to $\mathrm{BrS}$ from the point of view of the cellular-molecular mechanisms. ${ }^{20}$ $\mathrm{BrS}$ patients are sometimes categorized as ER variant. Thus, in some cases, it is difficult to distinguish ER syndrome from BrS. Kamakura et al reported that $16 \%$ of the patients diagnosed with ER syndrome were actually BrS with inferolateral ER pattern and a type 1 ECG only in the high intercostal spaces. ${ }^{21}$

The present study population was diagnosed with $\mathrm{BrS}$ according to diagnostic criteria. All patients recorded a type 1 ECG in the normal and/or high intercostal space position either at baseline or after the administration of a sodium-channel blocking agent. We diagnose only patients with ER pattern and a history of VTA and/or ES events without Brugada-type ECG as ER syndrome. Therefore, ER syndrome patients were not included in this study population. The prevalence of the ER pattern was 13/41 patients $(32 \%)$. Previous studies have been reported the prevalence of the ER pattern in the inferior, lateral or inferior + lateral leads as $10-12 \%$ of patients with BrS. ${ }^{13,21,22}$ The ER pattern frequently coexists in BrS, but the clinical importance of the ER pattern, especially in patients without 


\begin{tabular}{|c|c|c|c|}
\hline & $\underset{n=15}{\text { VTA events (+), }}$ & $\begin{array}{l}\text { VTA events (-), } \\
n=26\end{array}$ & $P$ value \\
\hline \multicolumn{4}{|l|}{ Demographic date } \\
\hline Sex male, $n(\%)$ & $14(93)$ & $26(100)$ & 0.366 \\
\hline Age (years) & $43 \pm 13$ & $47 \pm 13$ & 0.296 \\
\hline Family history of SCD, $\mathrm{n}(\%)$ & $3(20)$ & $7(27)$ & 0.619 \\
\hline History of syncope, n (\%) & $2(13)$ & $7(27)$ & 0.311 \\
\hline Documented history of VF, $\mathrm{n}(\%)$ & $11(73)$ & $7(27)$ & $0.008^{*}$ \\
\hline $\begin{array}{l}\text { Inducibility of VTA with programmed ventricular } \\
\text { stimulation, } \mathrm{n} / \mathrm{N}(\%)\end{array}$ & $6 / 7(85)$ & $20 / 22(91)$ & 1.000 \\
\hline \multicolumn{4}{|l|}{ Laboratory data } \\
\hline $\mathrm{Cr}(\mathrm{mg} / \mathrm{dL})$ & $0.82 \pm 0.12$ & $0.87 \pm 0.21$ & 0.568 \\
\hline $\mathrm{Na}(\mathrm{mEq} / \mathrm{L})$ & $140.8 \pm 1.7$ & $141.6 \pm 1.6$ & 0.141 \\
\hline $\mathrm{K}(\mathrm{mEq} / \mathrm{L})$ & $4.23 \pm 0.24$ & $4.11 \pm 0.40$ & 0.292 \\
\hline BNP (pg/dL) & $9.8 \pm 6.4$ & $16.1 \pm 19.7$ & 0.282 \\
\hline \multicolumn{4}{|l|}{ Echocardiographic parameters } \\
\hline $\mathrm{EF}(\%)$ & $69 \pm 5$ & $67 \pm 5$ & 0.326 \\
\hline LVDd (mm) & $46 \pm 6$ & $43 \pm 13$ & 0.444 \\
\hline LVDs (mm) & $28 \pm 9$ & $26 \pm 8$ & 0.733 \\
\hline \multicolumn{4}{|l|}{ Electrocardiographic parameters } \\
\hline No. of analyzed ECGs, $n$ & $38 \pm 20$ & $32 \pm 19$ & 0.313 \\
\hline Heart rate (beats/min) & $66 \pm 13$ & $67 \pm 10$ & 0.957 \\
\hline PR interval (ms) & $173 \pm 31$ & $157 \pm 21$ & 0.053 \\
\hline QRS duration (ms) & $111 \pm 14$ & $104 \pm 8$ & 0.056 \\
\hline QTc (ms) & $412 \pm 21$ & $402 \pm 21$ & 0.196 \\
\hline Spontaneous type 1 ECG, n (\%) & $9(60)$ & $8(31)$ & 0.067 \\
\hline Fragmented QRS, n (\%) & $4(27)$ & $3(11)$ & 0.215 \\
\hline S-wave in lead I, n (\%) & $8(53)$ & $12(46)$ & 0.751 \\
\hline S-wave in lead I $\geq 0.1 \mathrm{mV}, \mathrm{n}(\%)$ & $7(47)$ & $8(31)$ & 0.336 \\
\hline S-wave in lead I $\geq 40 \mathrm{~ms}, \mathrm{n}(\%)$ & $8(53)$ & $11(42)$ & 0.533 \\
\hline Tpeak-end interval (ms) & $112 \pm 21$ & $104 \pm 11$ & 0.120 \\
\hline Tpeak-end dispersion (ms) & $29 \pm 10$ & $25 \pm 10$ & 0.257 \\
\hline ER pattern, n (\%) & $7(47)$ & $6(23)$ & 0.168 \\
\hline ER pattern in lateral leads, $n(\%)$ & $1(7)$ & $2(8)$ & 1.000 \\
\hline ER pattern in inferior leads, $\mathrm{n}(\%)$ & $3(20)$ & $4(15)$ & 0.693 \\
\hline ER pattern in inferior + lateral leads, $n(\%)$ & $3(20)$ & $0(0)$ & $0.043^{*}$ \\
\hline Day-to-day variation of ER pattern, $n(\%)$ & $6(40)$ & $1(4)$ & $0.006^{*}$ \\
\hline Notching of ER pattern, $\mathrm{n}(\%)$ & $3(20)$ & $2(8)$ & 0.337 \\
\hline Slurring of ER pattern, $n(\%)$ & $6(40)$ & $4(15)$ & 0.130 \\
\hline ER pattern with ascending ST-segment, $\mathrm{n}(\%)$ & $3(20)$ & $5(19)$ & 1.000 \\
\hline $\begin{array}{l}\text { ER pattern with horizontal/descending } \\
\text { ST-segment, } n(\%)\end{array}$ & $4(27)$ & $1(4)$ & 0.051 \\
\hline
\end{tabular}

*Significance. Abbreviations as in Table 1.

\begin{tabular}{|c|c|c|c|}
\hline & HR & $95 \% \mathrm{Cl}$ & $P$ value \\
\hline Day-to-day variation of ER pattern & 3.475 & $1.105-10.414$ & $0.034^{*}$ \\
\hline Documented history of VF & 4.802 & $1.547-17.995$ & $0.006^{\star}$ \\
\hline
\end{tabular}

*Significance. $\mathrm{Cl}$, confidence interval; HR, hazard ratio. Other abbreviations as in Table 1.

preceding fatal arrhythmic events, is still controversial. ${ }^{21-25}$ A meta-analysis of the ER pattern and BrS concluded that BrS patients with the ER pattern were at high risk for future arrhythmic events. ${ }^{26}$ Furthermore, it also concluded that the ER pattern in the inferior + lateral leads was related to higher risk when it was followed by horizontal/descending ST-segment elevation. ${ }^{27}$ In this study, the incidence of the ER pattern itself did not differ between the patient groups with and without VTA/ES events, although the incidence of the ER pattern in the inferior+lateral leads and with 


\begin{tabular}{|c|c|c|c|}
\hline & $\underset{n=9}{\text { ES events }(+)}$ & $\begin{array}{l}\text { ES events }(-) \\
\quad n=32\end{array}$ & $P$ value \\
\hline \multicolumn{4}{|l|}{ Demographic date } \\
\hline Sex male, $n(\%)$ & $9(100)$ & $31(96)$ & 1.000 \\
\hline Age (years) & $41 \pm 14$ & $47 \pm 13$ & 0.232 \\
\hline Family history of SCD, $\mathrm{n}(\%)$ & $1(11)$ & $9(28)$ & 0.294 \\
\hline History of syncope, n (\%) & $1(11)$ & $8(25)$ & 0.373 \\
\hline Documented history of VF, $n(\%)$ & $7(78)$ & $11(34)$ & $0.028^{*}$ \\
\hline $\begin{array}{l}\text { Inducibility of VTA with programmed ventricular } \\
\text { stimulation, } n / N(\%)\end{array}$ & $3 / 4(75)$ & $23 / 25(92)$ & 0.371 \\
\hline \multicolumn{4}{|l|}{ Laboratory data } \\
\hline $\mathrm{Cr}(\mathrm{mg} / \mathrm{dL})$ & $0.83 \pm 0.13$ & $0.85 \pm 0.19$ & 0.795 \\
\hline $\mathrm{Na}(\mathrm{mEq} / \mathrm{L})$ & $140.6 \pm 1.9$ & $141.4 \pm 1.6$ & 0.171 \\
\hline $\mathrm{K}(\mathrm{mEq} / \mathrm{L})$ & $4.23 \pm 0.27$ & $4.13 \pm 0.36$ & 0.473 \\
\hline BNP (pg/dL) & $9.6 \pm 6.5$ & $14.9 \pm 17.8$ & 0.421 \\
\hline \multicolumn{4}{|l|}{ Echocardiographic parameters } \\
\hline $\mathrm{EF}(\%)$ & $69 \pm 4$ & $67 \pm 6$ & 0.301 \\
\hline LVDd (mm) & $46 \pm 6$ & $44 \pm 12$ & 0.679 \\
\hline LVDs (mm) & $29 \pm 10$ & $27 \pm 7$ & 0.590 \\
\hline \multicolumn{4}{|l|}{ Electrocardiographic parameters } \\
\hline No. of analyzed ECGs, $n$ & $39 \pm 22$ & $33 \pm 19$ & 0.464 \\
\hline Heart rate (beats/min) & $67 \pm 13$ & $66 \pm 13$ & 0.860 \\
\hline PR interval (ms) & $166 \pm 20$ & $162 \pm 28$ & 0.711 \\
\hline QRS duration (ms) & $112 \pm 16$ & $105 \pm 7$ & 0.054 \\
\hline QTc (ms) & $413 \pm 23$ & $404 \pm 21$ & 0.253 \\
\hline Spontaneous type 1 ECG, n (\%) & $5(56)$ & $12(38)$ & 0.450 \\
\hline Fragmented QRS, n (\%) & $2(22)$ & $5(16)$ & 0.637 \\
\hline S-wave in lead I, n (\%) & $5(56)$ & $15(47)$ & 0.719 \\
\hline S-wave in lead I $\geq 0.1 \mathrm{mV}$ & $4(44)$ & $11(34)$ & 0.701 \\
\hline S-wave in lead I $\geq 40 \mathrm{~ms}$ & $5(56)$ & $14(44)$ & 0.709 \\
\hline Tpeak-end interval (ms) & $115 \pm 23$ & $104 \pm 13$ & 0.069 \\
\hline Tpeak-end dispersion (ms) & $25 \pm 10$ & $27 \pm 10$ & 0.702 \\
\hline ER pattern, n (\%) & $5(56)$ & $8(25)$ & 0.113 \\
\hline ER pattern in lateral leads, $n(\%)$ & $1(11)$ & $2(6)$ & 0.535 \\
\hline ER pattern in inferior leads, $n(\%)$ & $2(22)$ & $5(16)$ & 0.642 \\
\hline ER pattern in inferior+lateral leads, $\mathrm{n}(\%)$ & $2(22)$ & $1(3)$ & 0.116 \\
\hline Day-to-day variation of ER pattern, $n(\%)$ & $5(56)$ & $2(6)$ & $0.003^{*}$ \\
\hline Notching of ER pattern, $\mathrm{n}(\%)$ & $3(33)$ & $2(6)$ & 0.061 \\
\hline Slurring of ER pattern, $\mathrm{n}(\%)$ & $4(44)$ & $6(19)$ & 0.185 \\
\hline ER pattern with ascending ST-segment, $\mathrm{n}(\%)$ & $3(33)$ & $5(16)$ & 0.236 \\
\hline $\begin{array}{l}\text { ER pattern with horizontal/descending } \\
\text { ST-segment, } n(\%)\end{array}$ & $2(22)$ & $3(9)$ & 0.298 \\
\hline
\end{tabular}

*Significance. Abbreviations as in Table 1.

horizontal/descending ST-segment elevation tended to be higher in patients with VTA/ES events. A univariate analysis of clinical variables was performed to identify more serious factors using a Cox proportional hazards regression model among BrS patients with the ER pattern (Supplementary Table 1). Documented history of VF events, day-to-day variation of the ER pattern that was in the inferior + lateral leads were predictors for future VTA events among BrS patients with the ER pattern. Previous studies mention that several ECG findings, such as spontaneous type 1 ECG, fragmented QRS, PR interval, QRS duration, $T$ peak-end interval, $T$ peak-end dispersion, and prominent $\mathrm{S}$-wave in lead I, were useful for risk stratification., ${ }^{\mathbf{1 7}-19}$ The incidence of these parameters did not differ between the patient groups with and without VTA/ES events in this study. Differences in the patients' characteristics might be responsible for this discrepancy with previous studies, or it might be related to the study design. Our study population was small and derived from a single center. The patients were at higher risk for arrhythmic events because they were recruited for ICD implantation based on common ICD indications.

\section{Day-to-Day Variation of ER Pattern in Patients With BrS}

The characteristics of the ER pattern and Brugada-type ST-segment elevation (i.e., amplitude and/or morphology) are known to be influenced by various factors, including drugs, autonomic tone, seasonal factors, etc., and this 
concept is understood as "dynamicity". ${ }^{10-13}$ Although there are some reports that emphasize the importance of the dynamicity of the ER pattern as an arrhythmogenic risk factor, ${ }^{10-13}$ the clinical implication is still controversial. Kitamura et al have reported that day-to-day variation of the ER pattern correlated with the incidence of VF history and VF recurrence during long-term follow-up of patients with vasospastic angina. ${ }^{28}$ This suggests a potential role of day-to-day variation of the ER pattern as a predictor of life-threatening arrhythmic events in at least some of the population. However, few of these reports have mentioned the dynamicity of the ER pattern in BrS. ${ }^{24}$ The clinical importance of the ER pattern in $\mathrm{BrS}$ is controversial in some reports, ${ }^{\mathbf{8} 20-23}$ which may be related to the stability of the presence of the ER pattern. The results of the present study may assist in settling the issue. Day-to-day variation of ER pattern was evaluated as a representative parameter of ER dynamicity, and it was compared among the patient groups with and without VTA/ES. Previous studies have reported that dynamicity of the ER pattern was prominent before VTA and/or ES events. ${ }^{10-13}$ However, the dynamicity of the ER pattern in the stable phase have not been evaluated in previous investigations. The present study results suggested that day-to-day variation of the ER pattern in the stable phase was associated with VTA/ES events.

Additionally, background differences between patients with and without day-to-day variation is an intriguing clinical question. Another comparison based on with/without day-to-day variation of the ER pattern in BrS patients was performed (Supplementary Table 2). VTA/ES events were more frequently observed in patients with day-to-day variation than in those without.

We could not distinguish between VTA and/or ES events caused by $\mathrm{BrS}$ or the ER pattern. Our present results may state the importance of dynamicity of the ER pattern as a predictive parameter for fatal arrhythmic events in patients with $\mathrm{BrS}$. The mechanism might be explained by variable and/or instable distribution of refractoriness in the ventricular wall, which causes phase 2 reentry as a trigger for VF. 9

Asymptomatic BrS, which is prevalent in $0.1-0.2 \%$ of the Japanese population, ${ }^{\mathbf{1 6}, 22,23}$ is prognostically benign compared with symptomatic BrS. The detection of the high-risk population and prevention of SCD among asymptomatic patients is important. Evaluation of the characteristics of the ER pattern, including dynamicity and localization, should be incorporated in risk stratification for life-threatening arrhythmic events in patient with $\mathrm{BrS}$. Furthermore, these evaluations play a role in risk management for VTA recurrence in patient with $\mathrm{BrS}$ and an ICD.

\section{Study Limitations}

The study population was small. Furthermore, because this was a single center clinical study, the indication for ICD implantation may pose a risk of selection bias. In addition, ECG recordings were only performed during the daytime in the outpatient clinic, so the day-to-day variation of ER pattern during the night was not evaluated. The number of recorded ECGs did not differ between the patient groups with and without VTA/ES events. However, our study design could not completely eliminate sampling biases due to the follow-up period and the number of recorded ECGs. We could not evaluate genotype and phenotype, which are important variables for BrS. Finally, we could not elucidate the mechanism of VTA and/or ES events caused by BrS or ER pattern. These points need to be evaluated in future studies in a larger study population.

\section{Conclusions}

The incidence of day-to-day variation of the ER pattern was higher in the patient group with arrhythmic events of VTA and/or ES. This result indicates that these might be possible predictors for future fatal arrhythmic events in BrS patients with an ICD.

\section{Disclosures}

This study received no financial support from commercial sources, and the authors state that they have no conflicts of interest. No specific unapproved use of any compound or product occurred. J.A. is a member of Circulation Journal's Editorial Board.

\section{IRB Information}

All studies were performed under approval from the Clinical Studies and Ethics Committee of Kitasato University Hospital, reference no. 12-26.

\section{Reference}

1. Brugada P, Brugada J. Right bundle branch block, persistent ST segment elevation and sudden cardiac death: A distinct clinical and electrocardiographic syndrome. A multicenter report. $J \mathrm{Am}$ Coll Cardiol 1992; 20: 1391-1396.

2. Kusumoto FM, Bailey KR, Chaouki AS, Deshmukh AJ, Gautam S, Kim RJ, et al. Systematic review for the 2017 AHA/ ACC/HRS guideline for management of patients with ventricular arrhythmias and the prevention of sudden cardiac death. Circulation 2018; 138: 421.

3. Shimizu W. Update of diagnosis and management of inherited cardiac arrhythmias. Circ J 2013; 77: 2867-2872.

4. Priori SG, Wilde AA, Horie M, Cho Y, Behr ER, Berul C, et al. HRS/EHRA/APHRS expert consensus statement on the diagnosis and management of patients with inherited primary arrhythmia syndromes: Document endorsed by HRS, EHRA, and APHRS in May 2013 and by ACCF, AHA, PACES, and AEPC in June 2013. Heart Rhythm 2013; 10: 1932-1963.

5. Haïssaguerre M, Derval N, Sacher F, Jesel L, Deisenhofer I, de Roy L, et al. Sudden cardiac arrest associated with early repolarization. $N$ Engl J Med 2008; 358: 2016-2023.

6. Rosso R, Kogan E, Belhassen B, Rozovski U, Scheinman MM, Zeltser D, et al. J-point elevation in survivors of primary ventricular fibrillation and matched control subjects: Incidence and clinical significance. J Am Coll Cardiol 2008; 52: $1231-$ 1238.

7. Tikkanen JT, Anttonen O, Junttila MJ, Aro AL, Kerola T, Rissanen HA, et al. Long-term outcome associated with early repolarization on electrocardiography. N Engl J Med 2009; 361: $2529-2537$.

8. Nam GB, Kim YH, Antzelevitch C. Augmentation of J waves and electrical storms in patients with early repolarization. $N$ Engl J Med 2008; 358: 2078-2079.

9. Antzelevitch C, Yan GX. J wave syndromes. Heart Rhythm 2010; 7: $549-558$.

10. Aizawa Y, Sato M, Ohno S, Horie M, Takatsuki S, Fukuda K, et al. Circadian pattern of fibrillatory events in non-Brugada-type idiopathic ventricular fibrillation with a focus on $\mathbf{J}$ waves. Heart Rhythm 2014; 11: 2261-2266.

11. Choi HO, Nam GB, Jin ES, Kim KH, Kim SH, Hwang ES, et al. Temporal variation and morphologic characteristics of J-waves in patients with early repolarisation syndrome. Heart 2013; 99: $1818-1824$

12. Miyazaki H, Nakagawa M, Shin Y, Wakisaka O, Shinohara T, Ezaki K, et al. Comparison of autonomic J-wave modulation in patients with idiopathic ventricular fibrillation and control subjects. Circ J 2013; 77: 330-337.

13. Takagi M, Aonuma K, Sekiguchi Y, Yokoyama Y, Aihara N, Hiraoka M; Japan Idiopathic Ventricular Fibrillation Study (J-IVFS) Investigators. The prognostic value of early repolarization ( $\mathbf{J}$ wave) and ST-segment morphology after $\mathbf{J}$ wave in Brugada syndrome: Multicenter study in Japan. Heart Rhythm 2013; 10: $5330-5339$. 
14. Credner SC, Klingenheben T, Mauss O, Sticherling C, Hohnloser $\mathrm{SH}$. Electrical storm in patients with transvenous implantable cardioverter-defibrillators: Incidence, management and prognostic implications. J Am Coll Cardiol 1998; 32: 1909-1915.

15. Antzelevitch C, Brugada P, Borggrefe M, Brugada J, Brugada R, Corrado D, et al. Brugada syndrome: Report of the second consensus conference: Endorsed by the Heart Rhythm Society and the European Heart Rhythm Association. Circulation 2005; 111: $659-670$.

16. JCS Joint Working Group. Guidelines for non-pharmacotherapy of cardiac arrhythmias (JCS 2011): Digest version. Circ J 2013; 77: $249-274$

17. Morita H, Kusano KF, Miura D, Nagase S, Nakamura K, Morita ST, et al. Fragmented QRS as a marker of conduction abnormality and a predictor of prognosis of Brugada syndrome. Circulation 2008; 118: 1697-1704.

18. Castro J, Antzelevitch C, Tornés F, Dorantes M, Dorticós F, Zayas $\mathrm{R}$, et al. Tpeak-Tend and Tpeak-Tend dispersion as risk factors for ventricular tachycardia/ventricular fibrillation in patients with the Brugada syndrome. J Am Coll Cardiol 2006; 47: $1828-1834$.

19. Calò L, Giustetto C, Martino A, Sciarra L, Cerrato N, Marziali $\mathrm{M}$, et al. A new electrocardiographic marker of sudden death in Brugada syndrome: The S-wave in lead I. J Am Coll Cardiol 2016; 67: 1427-1440.

20. Boineau JP. The early repolarization variant: An electrocardiographic enigma with both QRS and J-STT anomalies. $J$ Electrocardiol 2007; 40: 3.e1-10.

21. Kamakura T, Wada M, Nakajima I, Ishibashi K, Miyamoto K, Okamura H, et al. Significance of electrocardiogram recording in high intercostal spaces in patients with early repolarization syndrome. Eur Heart J 2016; 37: 630-637.

22. Kamakura S, Ohe T, Nakazawa K, Aizawa Y, Shimizu A, Horie $\mathrm{M}$, et al; Brugada Syndrome Investigators in Japan. Long-term prognosis of probands with Brugada-pattern ST-elevation in leads V1-V3. Circ Arrhythm Electrophysiol 2009; 2: 495-503.

23. Tokioka K, Kusano KF, Morita H, Miura D, Nishii N, Nagase $\mathrm{S}$, et al. Electrocardiographic parameters and fatal arrhythmic events in patients with Brugada syndrome: Combination of depolarization and repolarization abnormalities. J Am Coll Cardiol 2014; 63: 2131-2138.

24. Kawata H, Morita H, Yamada Y, Noda T, Satomi K, Aiba T, et al. Prognostic significance of early repolarization in inferolateral leads in Brugada patients with documented ventricular fibrillation: A novel risk factor for Brugada syndrome with ventricular fibrillation. Heart Rhythm 2013; 10: 1161-1168.

25. Letsas KP, Sacher F, Probst V, Weber R, Knecht S, Kalusche D, et al. Prevalence of early repolarization pattern in inferolateral leads in patients with Brugada syndrome. Heart Rhythm 2008; 5: $1685-1689$.

26. Georgopoulos S, Letsas KP, Liu T, Kalafateli M, Korantzopoulos $\mathrm{P}$, Bürkle $\mathrm{G}$, et al. A meta-analysis on the prognostic significance of inferolateral early repolarization pattern in Brugada syndrome. Europace 2018; 20: 134-139.

27. Sarkozy A, Chierchia GB, Paparella G, Boussy T, De Asmundis $\mathrm{C}$, Roos $\mathrm{M}$, et al. Inferior and lateral electrocardiographic repolarization abnormalities in Brugada syndrome. Circ Arrhythm Electrophysiol 2009; 2: 154-161.

28. Kitamura T, Fukamizu S, Hojo R, Aoyama Y, Komiyama K, Nishizaki M, et al. Early repolarization pattern and its day-to-day dynamic change as markers for ventricular fibrillation in patients with vasospastic angina. Europace 2016; 18: 1252-1258.

\section{Supplementary Files}

Please find supplementary file(s);

http://dx.doi.org/10.1253/circj.CJ-20-0142 